\title{
Determinants of Correct and Consistent Condom Use Among Mizan Tepi, University Students
}

\author{
Rameto Aman Nur \\ Department of Public health, Goba referral Hospital, Madawalabu University, Bale-Goba, Ethiopia.
}

\section{Email address:}

rametoaman@gmail.com

\section{To cite this article:}

Rameto Aman Nur. Determinants of Correct and Consistent Condom Use Among Mizan Tepi, University Students. Science Journal of Public Health. Vol. 3, No. 6, 2015, pp. 815-819. doi: 10.11648/j.sjph.20150306.13

\begin{abstract}
Introduction: In Ethiopia, HIV epidemic has been seen even in hard-to-reach and pastoralist communities. But the pattern and distribution of HIV greatly varies by various parameters like region, place of residence and sex. Even though it is a public health problem of all segment of the population, the epidemic among youth and economically active segment of the community is the fastest growing partly because of young people's vulnerability and because of low use of preventive services like correct and consistent condom use. Objectives: Assessment of determinants of correct and consistent condom use among Mizan-Tepi University students, southern, Ethiopia, 2011. Methods: Institutional based cross-sectional study design triangulated with qualitative study design was conducted. Data was collected from 421 randomly selected regular students using pretested structured questionnaire through interview. Coded, entered, cleaned and analyzed using SPSS version 16 Summary statistics of socio demographic variables were presented using frequency tables and graphs. A logistic regressions analysis method was employed. Odds ratio with $95 \%$ confidence interval was used to assess the association of dependent and independent variables. P-value less than $5 \%$ was taken into consideration to say there determinant factor. Results: A total of 421 students were participated in the study making the response rate $90.2 \%$. Out of the total respondents 301 (71.5\%) were males. The mean age of the study population was 17.3 with standard deviation of 2.41 years. The level of correct and consistent use of condom in the study is $43.3 \%$. Age at first sexual intercourse, number of sexual partner and own risk perception was found to be associated with correct and consistent use of condom. Conclusion: The overall prevalence of correct and consistent condom use is $43.3 \%$. Age at first sexual intercourse, number of sexual partner and own risk perceptions were found to be significant determinants of correct and consistent use of condom.
\end{abstract}

Keywords: Risk, Perception, Consistent, Correct, Mizan - Tepi University

\section{Introduction}

Since the beginning of the pandemic, HIV/AIDS has been spreading at an alarming rate worldwide and particularly in developing countries. Its impact goes beyond public health concerns as it undermines the social and economic structures particularly that of developing courtiers since it is affecting economically active segment of the population $[5,13]$.

The communities in age group between the 15 and 24 were severely affected segment of the population, and nearly $75 \%$ of all new HIV cases in this age group occur in women compared with males. In sub- Saharan Africa, the epidemic has increased due to sociocultural factors, behind which are gender inequalities $[6,10]$.

In Ethiopia, HIV epidemic has seen even the hard-to-reach and pastoralist communities. But the pattern and distribution of HIV greatly varies by various parameters like region, place of residence and sex [3].Even though it is a public health problem of all segment of the population, the epidemic among youth and economically active segment of the community is the fastest growing partly because of young people's vulnerability and because of low use of preventive services like correct and consistent condom use [7].

According to Ethiopia's 2007 single point estimates, the national adult (ages 15-49) HIV prevalence for 2008 was estimated to be $2.2 \%$ with an urban and rural HIV prevalence of $7.7 \%$ and $0.9 \%$ respectively [9].

Many study showed that correct and consistent use of condom during sexual intercourse to be one of important component of HIV prevention strategy. However its utilization is low and varies greatly from one target population to another.

Encouraging students to reduce risky sexual behaviors and 
to adopt safe sex practices like correct and consistent condom use during sexual intercourse is critical strategy emphasized by previous study as the most cost effective preventative strategies for prevention of HIV/AIDS and other STIs [11].

According to a study conducted among sexually active youths in Debre Birhan town, 38.7\% have ever used condom and $76.2 \%$ uses condom the last time they had sexual intercourse. Another study made on three small towns in North Gondar (Koladiba Chuahit, and Dabat) about condom utilization among commercial sex workers has indicated that only $32.5 \%$ of them have ever used condom while only $12.8 \%$ have used it consistently $[12,15]$.

Based on the result of the study conducted among commercial sex workers at Savannakhet,Lao PDR, variables that were significantly associated with consistent condom use were having worked as FSW less than 6 months compared to more than one year (OR: 6.15;95 \% CI: 1.83-20.60); $\mathrm{p}=$ 0.003 ), having a secondary level education or higher compared to primary education or lower (OR: 3.39; $95 \% \mathrm{CI}$ : $1.29-8.87 ; \mathrm{p}=0.013)$ and not having a regular partner $(\mathrm{OR}$ : 21.69; $95 \%$ CI: 7.98-58.93;p = 0.000) [1].

As per the study conducted among Ugandan university students, it was found that inconsistent condom use to be more prevalent among females as compared to males. Moreover, the impact of low condom efficacy on inconsistent condom use was considerably higher among females, compared with the impact among males. In general condom efficacy, frequency of alcohol consumption in relation to sexual intercourse was found to be significant determinant of inconsistent condom [4].

The result of the study conducted among youth in Debre Birhan town identified marital status, number of sexual partners and educational status of study participants to be significant determinants of correct and consistent condom use [15].

Correct and consistent condom use is a critical element in a comprehensive, effective and sustainable approach to HIV prevention and control. The male latex condom is the single most efficient available technology to reduce the sexual transmission of HIV and other sexually transmitted infections. [14].

Although some information on determinants of correct and consistent condom use among different target groups is available, there is scarcity of information on students in this regard. There is no similar study done in the current study area as well. Thus, this study intended to assess determinants of correct and consistent condom use among Mizan-Tepi University students which provide basic information for the University responsible bodies and varies stake holders to design effective and sustainable intervention program for prevention and control of HIV/AIDS.

\section{Method and Materials}

\subsection{Study Design}

Institutional based cross-sectional study design supplemented with qualitative approach was conducted.

\subsection{Study Setting and Period}

The study was conducted in Mizan-Tepi University from April to May 2011. The University was established in 2007/08 G.C.which is located in SNNPR of Ethiopia around $565 \mathrm{KM}$ far from Addis Ababa. The University is organized in two campuses, namely Mizan and Tepi campus from which the name Mizan Tepi University coined.

\subsection{Study Population}

Regular Students of Mizan-Tepi University.

\subsection{Sample Size and Sampling Procedure}

Four hundred sixty seven samples was calculated by using single population proportion formula by taking prevalence of consistent condom utilization of $12.8 \%$ which was taken from the study conducted on three small towns in North Gondar[12]. Study participants were selected by simple random sampling technique. For the qualitative part purposive sampling technique was used to select students.

\subsection{Data Collection Procedure}

Data was collected by structured and pre-tested selfadministered Amharic version questionnaire adapted from similar previous studies and sample of questions that modified to this study setting. Trained data collectors were involved in the pre-testing of the questionnaire and collection of the actual data. Focus group discussion was conducted by using focus group discussion topic guide to collect qualitative data. Tape recorder was used to record the discussion and a favorable place was given. The investigator moderated the discussion; the note taker encoded each discussant according to their seat arrangement and wrote down their code without missing their sequence of speech.

\subsection{Data Quality Assurance}

The English version questionnaire was translated into Amharic language and back translated to English to check its consistency by respective language expert. The data collectors as well as supervisor were trained on issue related to the overall data collection procedure. five percent of the questionnaire was pre-tested at Aman health science college to check acceptability and consistency and necessary correction was taken before the actual data collection. The completeness of the questionnaire was checked frequently by supervisors and principal investigator. Tape recorder was used to record the FGD and a favorable place was given to facilitate the confidentiality and quality of data.

\subsection{Data Processing and Analysis}

The quantitative data were coded, entered, cleaned and analyzed using SPSS version 16. Summary statistics of socio demographic variables were presented using frequency tables and graphs. Multiple logistic regression analysis was done to 
assess the association between the dependent variables and explanatory variables. Crude and adjusted Odds ratio with $95 \%$ confidence intervals was constructed. The qualitative study focused on the description of the status of correct and consistent condom utilization in the study population. Its analysis was done in parallel with the data collection. It includes the transcription and translation of the collected data. Each emerging theme was supported by direct (verbatim) quotations.

\subsection{Ethical Consideration}

Ethical approval was obtained from institute of research and community support core process office of Mizan-Tepi University. Informed verbal and written consent was secured from each college principal and respective students for their participation after the purpose of the study was clearly explained for them. The right to refuse was respected and the information collected from the students was kept confidential as the collected information was stored in a file without the name of study participant and not revealed to anyone except the principal investigator and kept locked with key.

\section{Results}

A total of 421 students were participated in the study making the response rate $90.2 \%$. Out of the total respondents $301(71.5 \%)$ were males. The mean age of the study population was 17.42 with standard deviation of 2.18 years.

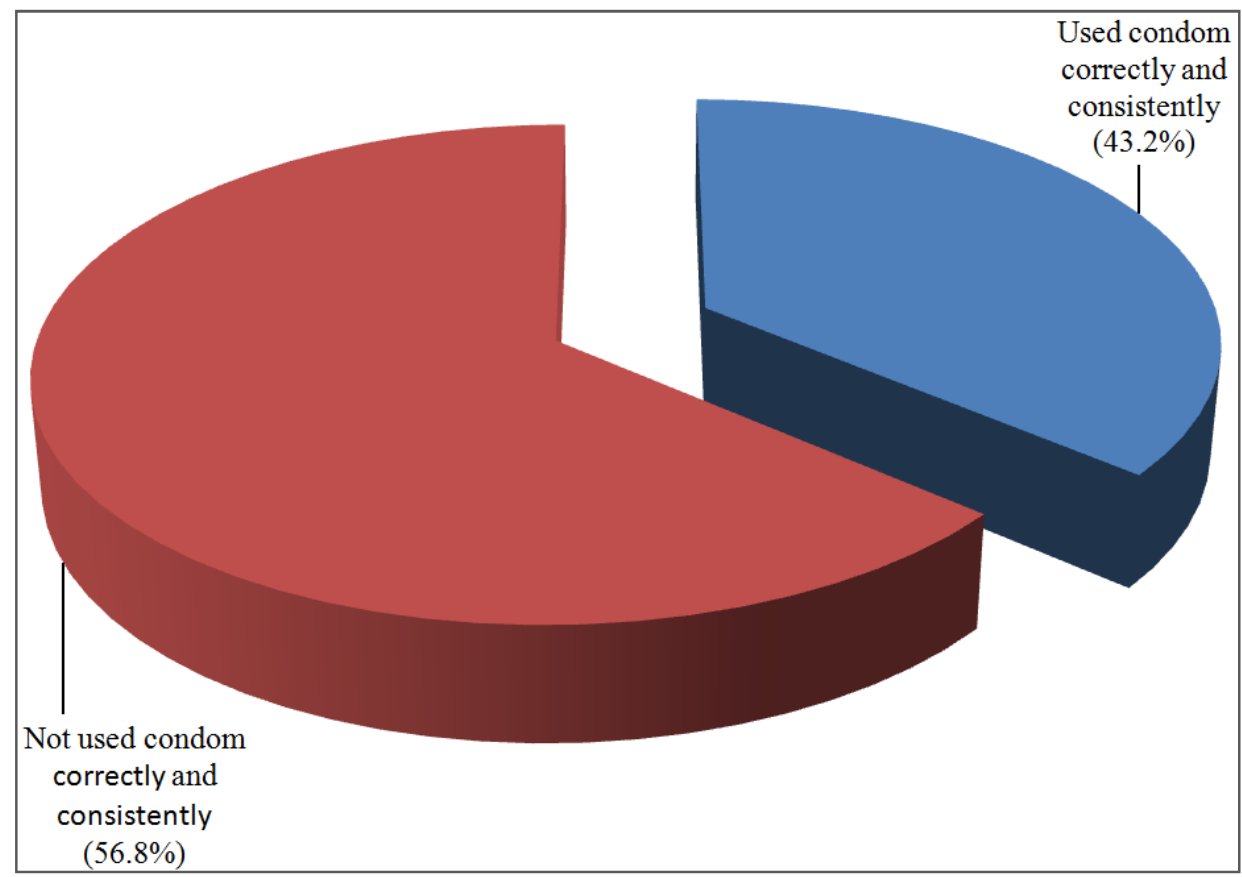

Figure 1. Correct and Consistent use of condom among sexually active Mizan Tepi university students Bench Maji and Sheka zone, SNNRS January, 2011.

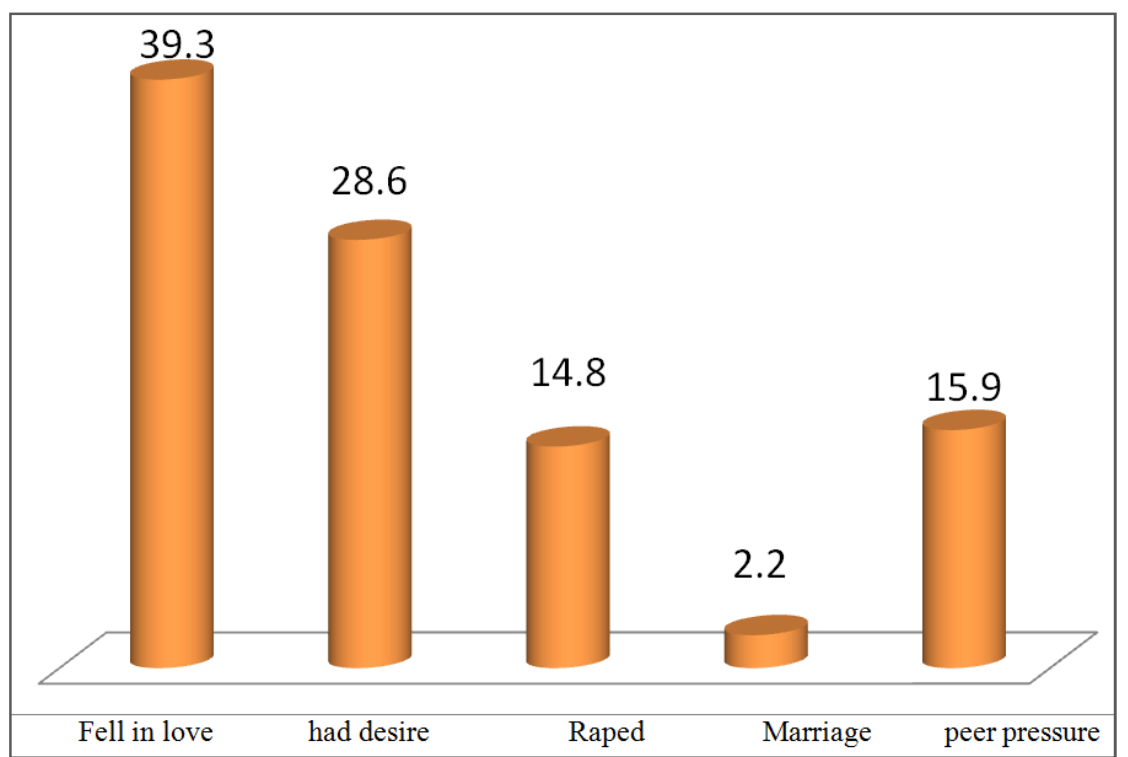

Figure 2. Reason to have sex among Mizan Tepi university students, south west Ethiopia January, 2011. 
Table 1. Distribution of socio-demographic characteristics and selected variables of Mizan Tepi university students.

\begin{tabular}{|c|c|c|}
\hline Variable & Frequency & Relative Frequency \\
\hline \multicolumn{3}{|l|}{ Sex } \\
\hline Male & 301 & 71.5 \\
\hline Female & 120 & 28.5 \\
\hline \multicolumn{3}{|l|}{ Age category } \\
\hline $15-19$ & 88 & 20.9 \\
\hline$>=20$ & 333 & 79.1 \\
\hline \multicolumn{3}{|l|}{ Religion } \\
\hline Orthodox & 195 & 46.3 \\
\hline Muslims & 108 & 25.7 \\
\hline Protestant & 90 & 21.4 \\
\hline Catholic & 9 & 2.1 \\
\hline Others & 19 & 4.5 \\
\hline \multicolumn{3}{|l|}{ Ethnicity } \\
\hline Oromo & 279 & 66.2 \\
\hline Amhara & 95 & 22.6 \\
\hline Tigre & 27 & 6.4 \\
\hline Kembata & 13 & 3.1 \\
\hline Others & 7 & 1.7 \\
\hline \multicolumn{3}{|l|}{ Marital status } \\
\hline Single & 348 & 82.6 \\
\hline Married & 51 & 12.1 \\
\hline Divorced/separated & 13 & 3.1 \\
\hline Widowed & 9 & 2.2 \\
\hline \multicolumn{3}{|c|}{ Age at first sexual intercourse } \\
\hline $15-19$ & 127 & 30.2 \\
\hline $20-24$ & 246 & 58.4 \\
\hline$>=25$ & 48 & 11.4 \\
\hline \multicolumn{3}{|c|}{ Number of sexual partners } \\
\hline One & 301 & 71.5 \\
\hline More than one & 120 & 28.5 \\
\hline \multicolumn{3}{|l|}{ Ever khat chewing } \\
\hline Yes & 397 & 94.3 \\
\hline No & 24 & 5.7 \\
\hline \multicolumn{3}{|l|}{ Ever had STIs } \\
\hline Yes & 87 & 20.7 \\
\hline No & 334 & 79.3 \\
\hline \multicolumn{3}{|l|}{ Ever alcohol drinking } \\
\hline Yes & 290 & 68.9 \\
\hline No & 131 & 31.1 \\
\hline
\end{tabular}

With regard to focus group discussion result, majority of students have mentioned that peer pressure, substance use along with friends (alcohol and khat), early marriage, rape and abduction in addition to cultural and economic factors to be the main reasons to involve early sexual activities. As the prevention methods of HIV/AIDS, limiting the number of sexual partners is a key for prevention of HIV/AIDS and other STIs.

One of female participant mentioned that there is misperception by students which related to denying of perceiving as if every person is at risk of the HIV/AIDS whether educated or not. According to participants, even though youth have high knowledge on HIV/AIDS they are poor in practicing HIV/AIDS prevention and control methods.

Nearly more than have of the discussants mentioned as they correctly and consistently used Condom during sexual intercourse in their life time by considering as if it is one of critical component of HIV prevention strategies. In contrary, others stated that reduction in sexual pleasure, shame to buy and lack of knowledge how use it are the main reason for not use condom.

Table 2. Comparison of selected variables and Correct and Consistent condom use among Mizan Tepi university students Bench Maji and Sheka zone, SNNRS January, 2011.

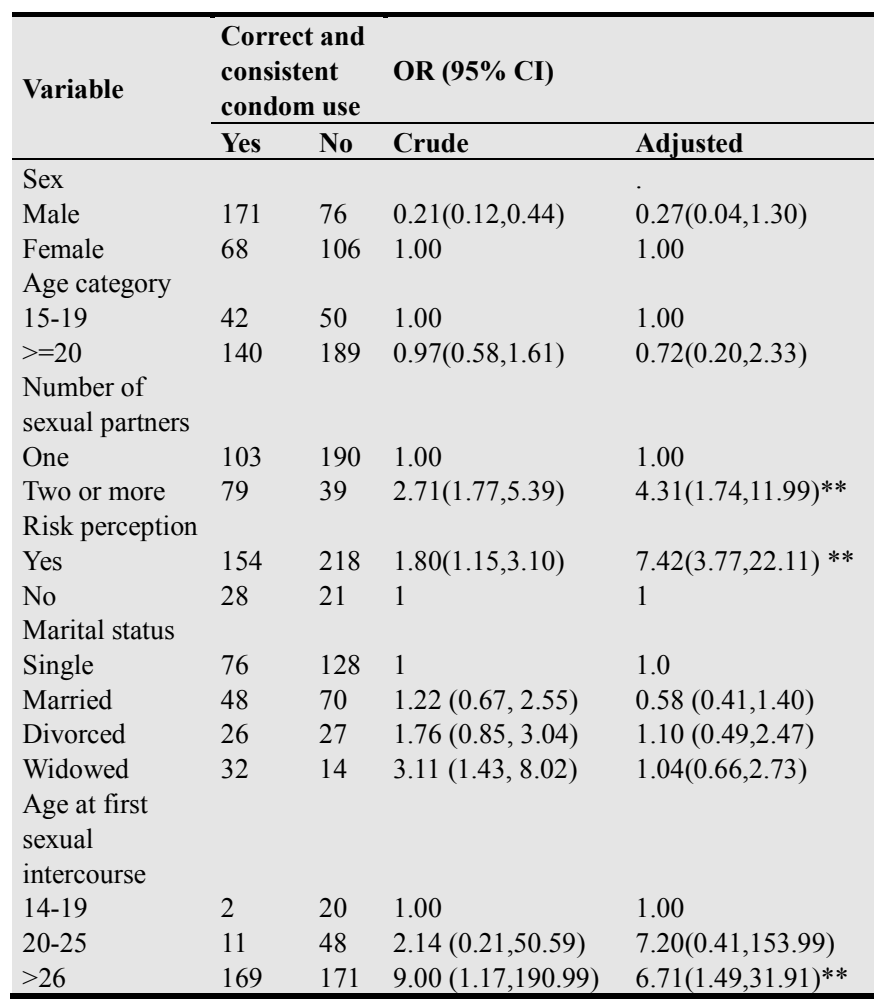

\section{Discussion}

Using condom correctly and consistently is a key component for HIV/AIDS prevention. In this study from the total of students ever had sex, only $182(43.3 \%)$ of students responded that they had correctly and consistently used condom.

The result is when compared with study conducted among sexually active respondents that revealed $30 \%$ of consistent and correct use of condom, study conducted among sexually active youths in Debre Birhan town, which showed $38.7 \%$ and study conducted on three small towns in North Gondar one (Koladiba Chuahit, and Dabat) about condom utilization among commercial sex workers that indicated only $32.5 \%$ respondents used condom consistently and correctly $[12,15]$. This could be time gap between the studies, the difference in composition of study participant and recent accelerated expansion of HIV related information and services.

Age at first sexual intercourse was significantly associated with correct and consistent condom use by students. Students started sexual intercourse at age of twenty six and above were nearly seven times more likely use condom correctly and consistently compared with those started in age group between 15-19 year $(\mathrm{AOR}=6.71$, 
95\%CI (1.49,31.91)).

It has been found that, number of sexual partner is significantly associated consistent and correct condom use by students. The odds of correct and consistent condom use by students is four times higher among those have single sexual partner compared with those have multiple sexual partner $(\mathrm{AOR}=4.31,95 \% \mathrm{CI}(1.74,11.99))$. This is consistent with the finding from research conducted among youth population in Debre Birhan town.

Own HIV risk perception found to be significant determinant factor for correct and consistent use of condom by students. Those students perceive themselves as at risk are seven times more use condom correctly and consistently $(\mathrm{AOR}=7.42,95 \% \mathrm{CI}(3.77,22.11))$. If a student is perceived as he/she at risk of HIV, the probability of using condom consistently and correctly will increase by far could be the possible reason.

But differ from result of the study conducted among commercial sex workers at Savannakhet,Lao PDR, were having worked as FSW less than 6 months, having a secondary level education or higher and not having a regular partner [1]. The possible reason could be study population difference. As per the study conducted among Ugandan university students on correct and consistent condom use, Condom efficacy, frequency of alcohol consumption in relation to sexual intercourse was found to be significant determinant of inconsistent condom which is not in line with this study [4].

\section{Conclusion}

The overall prevalence of correct and consistent use of condom in this study is $43.3 \%$. From the total study participants, around $15 \%$ of them had first sexual intercourse due to rap. Age at first sexual intercourse, number of sexual partner and own HIV risk perception were significantly associated with correct and consistent use of condom. In the qualitative part it was mentioned that, as to prevention methods of HIV/AIDS, limiting the number of sexual partners is a key for prevention of HIV/AIDS and other STIs.

\section{Acknowledgements}

First of all we would like to acknowledge Mizan Tepi University, institute research and community development and support for encouraging us and funding for the study. We would also like to extend our sincere thanks to health science and staffs for their continuous support throughout the process. We wish to express our deep appreciation to all study participants for their cooperation and willingness in providing valuable information. Last but not least we wish to thank all data collectors, supervisors, and all our friends who supported us in all efforts to accomplish the study.

\section{References}

[1] Ahimbisibwe E, Odwee J. and Ayiga N. Risk perception and condom use in Uganda. African population studies vol. 18(1):68-80.

[2] Carin H. Andrews. et al. Determinants of consistent condom use among female sex workers in Savannakhet, Lao PDR.

[3] CSA, ORC Macro (2006) Ethiopia Demographic and Health Survey 2005. Central Statistical Agency and ORC Macro.

[4] Devika Mehra ...etal Inconsistent condom use among Ugandan university students from a gender perspective: a cross-sectional study, 2010.

[5] Federal Ministry of health and /Federal HIV/AIDS Prevention and Control Office report 2007.

[6] Gary B, Christine R. Young men and construction of masculinity in sub-Saharan Africa: implications of HIV/AIDS conflict and violence. In: Social development papers, conflict prevention and reconstruction, Paper No. 26. Washington, DC: World Bank; 2005.

[7] Georges G, Nyovani JM (2007) HIV/AIDS and Sexual-Risk Behaviors among Adolescents: Factors influencing the use of condoms in Burkina Faso. Afr J Reproductive Health 11: 182196.

[8] Getu D. Knowledge and practice of condom in preventing HIV/A/IDS infection among commercial sex workers. EJHD.1999.

[9] Ismail S, Bistuamlak $\mathrm{H}$, and Alemu D. High-risk sexual behaviors for STD/HIV pregnancies and contraception among high school students in a rural town Northwestern Ethiopia. Ethiop. J. Health Dev. (1): 29-36.

[10] Kaye DK. Gender inequality and domestic violence: implications for human immunodeficiency virus (HIV) prevention. Afr Health Sci 2004; 4: 67 _70.

[11] Kennedy CE, Medley AM, Sweat MD, O’ Reilly KR (2010) Behavioral interventions for HIV positive prevention in developing countries: a systematic review and meta-analysis. Bull World Health Organ 88(8): 615-623.

[12] Kidane A. Sexuality, perception of risk of HI?V/STIs and condom use among high school adolescents in south Gondar, Amhara Region, (thesis ) Department of Community Health, Faculty of Medicine, Addis Ababa Unversity,2004.

[13] MOH. National Guidelines for voluntary HIV counseling and Testing in Ethiopia, Addis Ababa, Ethiopia.2000.

[14] UNAIDS Report on the global AIDS epidemic' 2008/9. Latest data update 9/8/2008 9:41:00 AM. Available at URL:http://WWW.unaids.org/en/knoledgecentre/HIVdata EPi.

[15] Zebideru Z. Assessment of HIV risk perception and condom use among youth in Debre Birhan town, Amhara region April 2005. 